brought out--the early diagnosis and early operation. This case occurred in the third week. The first symptom to suggest perforation was abdominal pain, cceurring about 7 o'clock in the morning. The man was operated on at 3 o'clock of the same day in his house, after very careful preparation of the room and the securing of assistants, nurses, etc. The perforation was found about eight or nine inches from the ileocecal valve, a small round perforation such as would be made by a 22-caliber rifle bullet. After closing the perforation with Lembert sutures, it seemed that the lumen of the gut had been so much encroached on that there was danger of obstruction. Dr. Batchelor eut out the stitches, took out the threads and made a circular purse-string suture, which seemed to close the opening satisfactorily and with a less degree of narrowing of the lumen of the intestine. The man recovered, and in the subsequent treatment Dr. Batchelor made use of the saline solution, something as suggested by Dr. Murphy, but not so much with the idea of washing out the bowel as to bring in nourishment. The saline solution was put in by means of a fountain syringe, and the discharging pipe was clamped off. The solution was admitted drop by drop and was used constantly. It scemed to take the place of nourishment and of drink and worked satisfactorily. Another little thing in, connection with this was that the anal pipe was a small catheter, on the supposition that anything larger would be expelled; but with a small catheter inserted, 16 to 18 size, the sphincter seemed to be very tolerant. Dr. Batchelor emphasized the two points, the early diagnosis and the prompt and quick operation, and he thinks that the sudden onset of pain and the restrieted abdominal motion are the two points one would rest most largely on in making a diagnosis. He considers those two symptoms of far more importance than changes in the pulse rate and temperature.

DR. J. E. Allaben, Rockford, Ill,, said, in regard to the symptoms about which Dr. Murphy spoke, that it has generally been considered that those symptoms are caused entirely by the absorption of septic material. The experiments of Buxton demonstrate that it is usually not the absorption of septic material but the absorption of large quantities of bacteria, which undergo disintegration in the blood and liberate their endotoxins, producing the symptoms of shock and collapse. Regarding Dr. Hammond's remarkś, Dr. Allaben did not see how he had any foundation for saying, so far as this particular case is concerned, that there was intestinal disease previous to the typhoid fever. He did not agree to that, because there had been no indications of intestinal disease at any time before the attack of typhoid, and he did not believe that intestinal disease ever existed. The perforation undoubtedly occurred from the ulceration of a solitary gland caused by infection from the typhoid bacillus. With reference to Dr. Fox's patient who died from neglect to open an abscess, Dr. Allaben suggested that the case was one of appendicitis complicating typhoid fever. The appendix is often infected in typhoid by the typhoid bacillus, and it must be apparent to all that appendicitis mav complicate typhoid. a simple appendicitis occurring in the course of typhoid. That is one of the things one must look for, and operation in such cases is always followed by excellent results. Regarding Dr. Bartlett's suggestion to stitch the perforation of the intestine into the abdominal wound, he thought that this procedure might be satisfactory if one could be sure that there is but one perforation. Other perforations may be present and be overlnoked. Again, obstruetion might be produced by kinking of the intestine. In all cases of septic peritonitis, the formation of adhesions is avoided by early evacuation of septic material. Adhesions are caused by the advancement of septic peritonitis. By operating early, these adhesions are limited.

Surgical Treatment of Goiter.-Dr. George A. Bingham, Toronto, in his presidential address before the Ontario Medical Association, May. 1907 (Canada Lancet, July 1907), states that in goiters affecting both lobes his experience has shown that it is not enough to remove one lobe and the isthmus, as cystic degeneration will continue in the remaining lobe. It would seem to be safer, after having removed the lobe most affected, with the isthmus, to ineise the capsule of the remaining lobe and to enucleate every cyst to be found.

\section{A CASE OF INFANTILE MYXEDEMA.}

\section{JAMES FREDERICK CLARKE, M.D.} FAIRFIELD, IOWA.

The case here presented is the fourth of sporadic cretinism brought to my attention in this part of Iowa. Such a number found in a limited territory inclines me
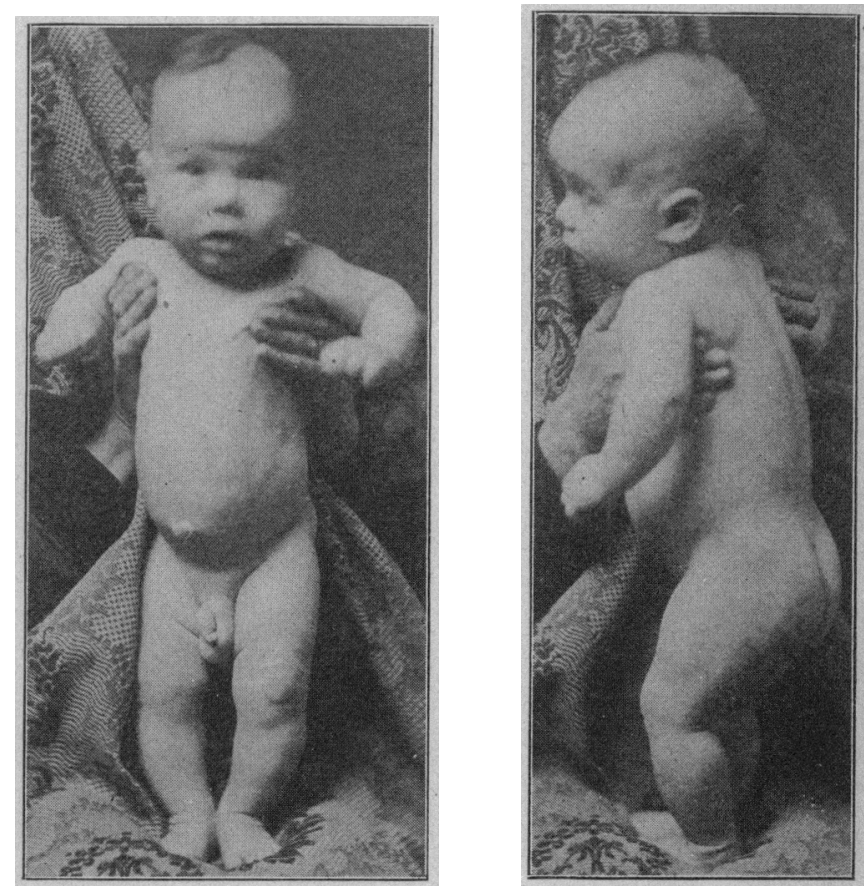

Fig. 1.-The child at beginning of thyroid treatment, March 18, 1906 .

Fig. 2.-Profile of child, March 18, 1906, at beginning of treatment
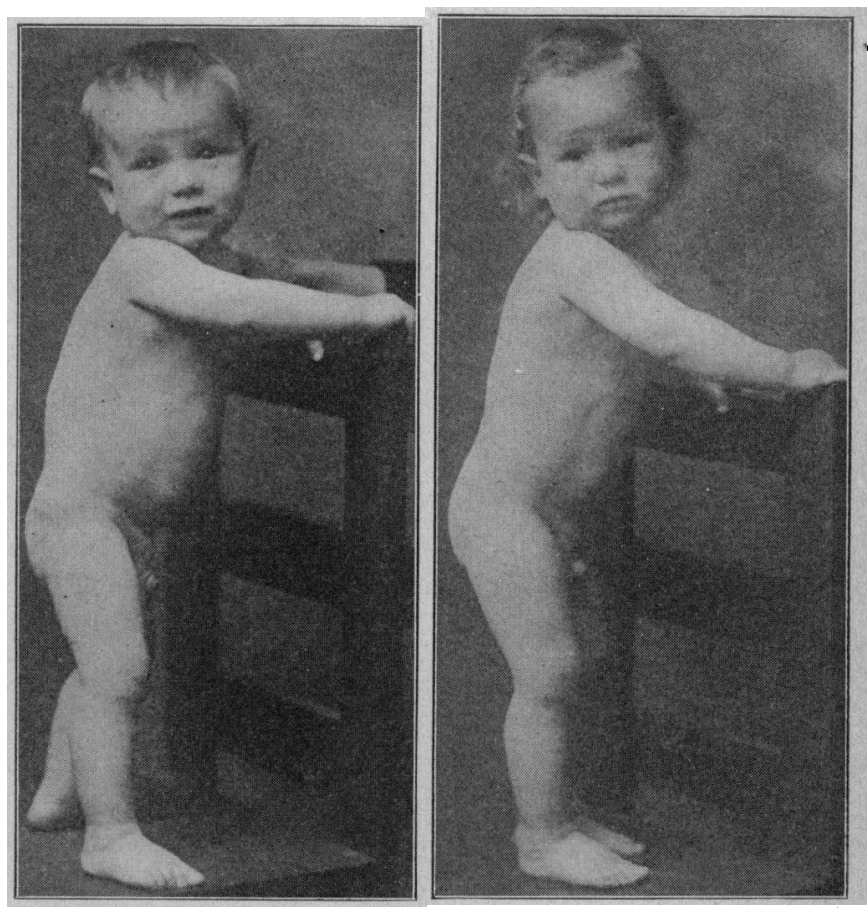

Fig. 3.-Child after less than seven months' thyroid treatment, Oct. 4, 1906 .

Fig. 4.-Child after fourteen months' treatment, May 27, 1907.

to the belief that the condition is much more frequent in the United States than is commonly supposed.

Patient.-P. Z., male, aged 18 months, was sent to me by Dr. C. S. Bishop of Glasgow, Iowa. 
History.-This boy was the fourth child, of German parents who are first cousins. All other children of the family are normal. The baby weighed ten pounds at birth (Oct. 25, 1904), fourteen pounds when two months old, and sixteen pounds when eight months of age. There was obstinate constipation from the second month, and when nine months old the baby became deeply jaundiced and remained so for several months. An umbilical hernia developed at the same age. From the age of 9 months there had been neither growth in heighth nor development in any way except the cutting of two lower incisors at 13 months.

First Examination.-March 18, 1907. The condition at 18 months of age is shown in the accompanying illustrations (Figs. 1 and 2). There was myxedema, inability to stand or sit alone, and an expression of imbecility. The height was $261 / 4$ inches and the weight 17 pounds 6 ounces. The fontanel was open; the hair harsh and worn off except on the top of the head. The skin was dry and sallow. The lower two in. eisors were the only teeth present. The tongue did not protrude. The legs were bowed and the abdomen prominent. The child never spoke and did not cry aloud. It was difficult to attract his attention but occasionally he smiled. He slept only at night.

Treatment.-Tbyroid feeding was begun March 18, 1906, by giving one-quarter of one two-grain tablet three times a day. For more than four months this amount could not be in creased without making the baby nervous and sleepless. Improvement began at once and has been continuous.

June 1, 1906: There were four teeth, new soft hair, and the baby was able to sit alone.

Oct. 4, 1906: He had fifteen teeth, weighed 24 pounds. and could stand. alone. The photograph (Fig. 3) of this date shows a loss of the myxedema and a marked change in the facial expression.

May $2 \overline{\bar{\lambda}}, 190 \bar{\tau}$ : The weight was 28 pounds; there were sixteen teeth. The baby had been walking for a month and could speak several words. He was apparently in a normal condition (Fig. 4), growing and developing as do other children, and while taking one two-grain thyroid tablet a day continuous!y, there is every reason to believe that he will continue to develop as a normal child.

\section{RIERS TREATMENT ("STAUUNGS-HYPER- AMIE") IN CHRONIC AND ACUTE SUR- GICAL INFECTIOUS DISEASES.*}

WILLY MEYER, M.D.

I'rofessor of Surgery at the New York Postgraduate Mfedical School and Hospital; Attending Surgeon to the German Hospital; Consulting Surgeon to the New York Skin and Cancer Ilospital and New York Infirmary.

$$
\text { NEW YORK CITY. }
$$

Principally for the sake of starting a discussion in our Section "on a subject that has been so thoroughly ventilated by surgcons abroad, particularly in Germany, during the last few years, I am going to make some remarks on Bier's Stauungs-Hypercemie in the treatment of chronic and acute surgical infections.

Ever since it was first published, ${ }^{1}$ in 1892 , I have used Bier's method whenever indicated, and have made many interesting and surprising observations. Little has so far been written about the subject on this side of the Atlantic.

We have with us to-day Dr. V. Schmieden, who, on May 7 of this year, as representative of his chief, Prof. A. Bier, on invitation of the Surgical Section of the National Association for the Study and Prevention of Tuberculosis, read a paper on "The Treatment of Bone

* Read in the Section on Surgery and Anatomy of the American Medical Association, at the Fifty-eighth Annual Session, held $a$. Atlantic City, June, 1907.

1. Verhandl. der deutschen Gesellsch. fïr Chirurgie, 1892, vol. I. p. 91 . and Joint Tuberculosis by Stauungs-Hyperamie" before its third annual meeting, held at Washington, and I am glad to avail myself of this opportunity to report to you my own experience with Bier's treatment, gathered within the last fifteen years.

The idea of making use of an increased volume of blood in and around the diseased focus was conceived by Bier during his studies of the observations of the late Prof. v. Rokitansky, the renowned Viennese pathologist, who found that patients who had suffered from stasis in tbe pulmonary circulation, due to heart disease or curvatures of the spine, never showed an active tuberculous lung affection on postmortem examination. On the other hand, it had been often seen that patients suffering from diseases of the heart, that produce a certain amount of anemia of the lungs (stenosis of pulmonary artery) are especially subject to tuberculous disease of the lungs. ${ }^{2}$

Bier's first attempts at the surgical clinic in Kiel, Germany, with active (arterial) hyperemia, by means of prolonged hot baths, or, locally, by means of the application of glass cups (suction method, cupping) proved unsatisfactory. He, therefore, tried the elastic rubber bandage, which his chief, Prof. v. Esmarch, had so successfully made use of for producing artificial anemia in cases of amputation and other operations on the extremities. Winding the elastic bandage gently around the limb above the seat of the disease, the thinwalled veins were naturally much more readily compressed than the firmer arteries, and while the latter continued to pump blood into the parts below the constriction, the return of the blood thus became interfered with; a partial stasis of venous blood was produced and could be maintained at will. This is the nucleus of the so-called "Bier's treatment" by means of the elastic bandage.

Fully appreciating the significance of the principle discovered. an original worker of the stamp of Bier was not to be baffed by difficulties. He clung to the further elaboration of his idea, practically applying it on the extensive material offered by the surgical clinics at Kiel and later Greifswald, to which latter place he was soon called as chief of clinic.

After a few communications, scattered in German wecklies, he published his well-known book on "Hyperämie als Heilmittel" (hyperemia as a therapeutic agent) in 1893. But in spite of the wealth of new and interesting observations brought out in his book, comparatively few surgeons, seemed to avail themselves of the advantages of the method, at least judging from the scanty contributions to the literature of the subject. Only a few men in the surgical world raised their voices in favor of it, among them the late v. Mikulicz. Undaunted by this seeming indifference on the part of the profession, Bier and his assistants again and again rointed out the benefit to be derived by the treatment. In spite of all his excellent work, it is, however, quite possible that the method would never have attained to its present general recognition had not Bier, especially since his call to Bonn to succeed the renowned Schede as chief of the surgical clinic, with wonderful tenacity and courage, extended the use of artificial hyperemia to inflammatory surgical infections of acute character, thus overthrowing, as it were, all time-honored views as to inflammatory processes and their surgical treatment by ice, elevation and rest. Since then the interest in Bier's work has been steadily and rapidly growing. Only a short

2. Farre and Travers, 1815; Louis, 1826 ; Frerichs, 1853. 